\title{
Stationary Digital Tomosynthesis
}

National Cancer Institute

\section{Source}

National Cancer Institute. Stationary Digital Tomosynthesis. NCI Thesaurus. Code C126696.

Digital tomosynthesis that uses an array of $\mathrm{x}$-ray sources to obtain cross-sectional images of an object for 3-D image construction. Stationary digital tomosynthesis eliminates the blur associated with a moving $x$-ray source and also decreases the time needed to obtain the images. 